\title{
RAPID METHOD OF FRIEDEL-CRAFTS ALKYLATION OF PHLOROGLUCINOL BY MICROWAVE IN DRY MEDIA AND REUSABLE CATALYST
}

\author{
ALEJANDRA P.VERGARA ${ }^{1,2}$, JAVIER A.CONTRERAS ${ }^{2}$, MAURICIO E. OSORIO'2 AND MARCELA A. CARVAJAL ${ }^{1,2 *}$
}

${ }^{I}$ Centro de Biotecnología "DAL” y Laboratorio de Productos Naturales, Departamento de Química, Universidad Técnica Federico Santa María, Av. España 1680, Postal code 2390123, Valparaíso, Chile.

\begin{abstract}
A new rapid and efficient method for the synthesis of a series of alkylated phloroglucinols using conventional microwave is reported 4 phloroglucinol derivatives $(4,5,6$ and 7$)$ were synthesized with good yields $(\sim 50 \%)$ by a Friedel-Crafts reaction through an Electrophilic Aromatic Substitution mechanism between geraniol/prenol and phloroglucinol, using reusable $\mathrm{SiO}_{2}$ and $\mathrm{AgNO}_{3}$ as the best catalyst tested without solvents under microwave irradiation.
\end{abstract}

Keywords: Microwave synthesis; alkylated phloroglucinol; $\mathrm{AgNO}_{3}$

\section{INTRODUCTION}

Nowadays, Organic Chemistry is becoming increasingly based on finding new technologies and alternative processes to existing ones that will be environmentally friendlier and less toxic (Green Chemistry). Organic synthesis processes are not exempt from this trend, because many of these involve solvents or solutions difficult to recycle after reaction and in some cases are highly toxic. Chemical synthesis assisted by microwave is a powerful tool, which when applied to a wide range of chemical reactions allows for important contributions such as: reducing reaction times, high yields, avoiding collateral and substitute products, and the use of toxic solvents.

Prenylated and geranylated phenols correspond to an interesting group of marine and plant natural products, with a wide variety of biological activities described, including anti-inflammatory ${ }^{1,2}$, antifungal ${ }^{3}$, anti-HIV ${ }^{4}$, antiAlzheimer activity, and most frequently - antineoplastic properties ${ }^{6,7}$ OrthoPrenylated phenols and Ortho-Geranylated play an important role in mediating many biological processes. Such an important structural motif needs a general strategy for its preparation, particularly for systems in which other aromatic hydroxyl residues are differentiated or present, as is often the case with natural therapeutic products containing this pharmacophore ${ }^{8}$. Terpenylphenols are isolated from natural sources with very low yield, and for that reason during the past few decades considerable research effort has focused on obtaining these compounds by synthesis. Within the alkylated phenols of interest in the area of Biology, the phloroglucinol derivatives can be highlighted. Their structural complexity when phloroglucinol is alkylated draws attention; because in gener$\mathrm{al}$, it is a challenge to attempt to incorporate nonpolar chains in a tri-substituted aromatic ring with $\mathrm{OH}$ groups (electron donating group).Among the most common synthetic strategies reported for the introduction of nonpolar chains in an aromatic ring (C-Alkylation) are: Friedel-Crafts reactions, Michael addition and multistep processes consisting of a neutral-pathway leading to the early $\mathrm{O}$-alkylation, followed by a series of ionic rearrangements resulting finally in C-alkylations. ${ }^{9}$ There are many publications that report different methods for accomplishing these coupling reactions in the synthesis of prenyl phenols and geranylphenols ${ }^{8,10-12}$, most with low yields and using highly toxic homogeneous and heterogeneous (solid) catalysts such as $\mathrm{HF}_{2} \mathrm{H}_{2} \mathrm{SO}_{4}, \mathrm{AlCl}_{3}$, or $\mathrm{BF}_{3}{ }_{3}^{13,14}$. But there are no reports of Friedel-Crafts allylation of the phloroglucinol molecule, via microwave mediated Electrophilic Aromatic Substitution (EAS). Reporting shortage can be due to the fact that the phloroglucinol molecule is rich in electrons for which it tends to suffer oxidation during synthesis. Using microwaves decreases the likelihood of oxidation by reducing reaction times. Accordingly, the development of more efficient methods is still in demand.

Late transition metals -the so-called coinage metals- are widely used for various organic transformations $s^{15}$, these include copper, silver, and gold. There are certain advantages of silver catalysts that make them a very appealing alternative. Shorter reaction times, increased stability toward exposure to air or moisture, and ease of preparation and storage of the catalyst are some of the highly beneficial properties of silver catalysts. Silver (I) is considered to be a mild oxidizing agent, suitable for efficient oxidation of primary and secondary alcohols to aldehydes and ketones. Owing to such properties, $\mathrm{Ag}_{2} \mathrm{CO}_{3}$ and $\mathrm{AgNO}_{3}$ (the complex of $\mathrm{AgNO}_{3}$ with ammonia is well-known as Tollens' reagent) are commonly used for the preparation of carbonyls from the corresponding alcohols under mild conditions ${ }^{16}$.
Here, we report an eco-friendly synthetic procedure focusing on conventional microwave-assisted reactions for the synthesis of alkylated phloroglucinol (alkylated Prenyl and Geranyl) using $\mathrm{AgNO}_{3}$ as a catalyst and silica gel as reaction support. On the other hand, the orientation in electrophilic aromatic substitution of the geranyl and prenyl chain was directed in ortho position according to the location the $\mathrm{OH}$ groups in the aromatic system.

\section{EXPERIMENTAL}

All purchased chemical reagents (Merck or Sigma-Aldrich) were of the highest purity commercially available, and were used without previous purification. Microwave irradiation was carried out with a domestic microwave oven (Thomas TH-18MCB, operating at $2450 \mathrm{MHz}$ ). IR spectra were recorded as thin films in an FT-IR Nicolet 6700 spectrometer and frequencies are reported in $\mathrm{cm}^{-1}$. Mass spectra were obtained by a Bruker Daltonics Microflex MALDITOF (Bruker Daltonics Inc., MA-USA), in positive ion mode and negative ion mode using detection by reflection with $\alpha$-cyano-4-hydroxycinnamic acid (CHCA) and 2,5-dihydroxybenzoic acid (DHB) $(1 \mathrm{mg} / \mathrm{mL}$, from Thermo Scientific Pierce) as matrices.To control the spectrometer the FLEXCONTROL 3.0 program was used (Bruker Daltonik $\mathrm{GmbH}$, Alemania). Data analysis was performed with the mMass v. 5.5.0 program.

${ }^{1} \mathrm{H}-,{ }^{13} \mathrm{C}-\mathrm{DEPT} 135$, sel. 1D ${ }^{1} \mathrm{H}$ NOESY, 2D HSQC and 2D HMBC spectra were recorded in $\mathrm{CDCl}_{3}$ solutions and are referenced to the residual peaks of $\mathrm{CHCl}_{3}$ at $\delta 7.26 \mathrm{ppm}$ and $\delta 77.0 \mathrm{ppm}$ for ${ }^{1} \mathrm{H}$ and ${ }^{13} \mathrm{C}$, respectively, on a Bruker Avance 400 Digital NMR spectrometer, operating at $400.1 \mathrm{MHz}$ for ${ }^{1} \mathrm{H}$ and $100.6 \mathrm{MHz}$ for ${ }^{13} \mathrm{C}$. Chemical shifts $(\delta)$ are reported in ppm and coupling constants (J) are given in Hz. Silica gel (60, 200-400 mesh) was used for C.C. and silica gel plates HF-254 for TLC. TLC spots were detected by heating after spraying with $25 \% \mathrm{H}_{2} \mathrm{SO}_{4}$ in $\mathrm{H}_{2} \mathrm{O}$.

\subsection{Synthesis of Prenyl-, and Geranyl- Phloroglucinols}

The alkylated derivatives of phloroglucinol were prepared by irradiation at $52.35 \mathrm{~W}$ microwave power (according to the Standard Test Method for Calibration of Microwave Ovens, ASTM) of a mixture of phloroglucinol (1) and $\mathrm{SiO}_{2}-\mathrm{AgNO}_{3}$. The reaction mixture was irradiated at different times depending on the type of allyl alcohol used, geraniol (2) or prenol (3) (Scheme 1). The reaction to produce derivatives of geranylated phloroglucinol was performed in microwaveable glass bottles $(250 \mathrm{ml})$ with a lid. For every 50 grams of silica gel impregnated with $\mathrm{AgNO}_{3}$ (prepared with a saturated solution of the dissolved salt in an ethanol water mixture 1:1), 15 grams (119 mmol) of commercial phloroglucinol and 37 grams $(240 \mathrm{mmol})$ of commercial geraniol are added (molar ratio 1:2); the mixture is homogenized and is introduced into the domestic microwave at its minimum power $(52.35 \mathrm{~W})$ at $50^{\circ} \mathrm{C} \pm 5^{\circ} \mathrm{C}$. After irradiation time between each round, the temperature is measured in the sample and the reaction is quenched, immersing the flask in ice water (close to $4{ }^{\circ} \mathrm{C}$ ) (between each round it is checked whether the reaction is complete by TLC). Round is understood as each time the bottle was subjected to microwave irradiation. The samples were subjected to different irradiation times and rounds, so as to determine the optimum reaction conditions. Once the rounds are completed, both the aroma and color of the mixture change; this indicates that the product is already synthesized. The dry mixture is again subjected to microwave irradiation under the same conditions. In subsequent times after the 
first reaction, only silica- $\mathrm{AgNO}_{3}$ is added, impregnated with phloroglucinol recovered from the filtrate of the same above reaction, plus 6 grams $(39 \mathrm{mmol})$ of geraniol in each repetition; thus ensuring that all the phloroglucinol reacts. This process is repeated until all the initial phloroglucinol has reacted. After the reaction, the $\mathrm{AgNO}_{3}$ must be removed from the reaction. This is done by doing 2 washes in a 1:1 ratio saturated solution of $\mathrm{NaCl}$ and dichloromethane in a separating funnel.

The reaction to produce prenylated phloroglucinol derivatives was performed in microwaveable glass bottles $(250 \mathrm{ml})$ with lids. For every 50 grams of silica gel impregnated with $\mathrm{AgNO}_{3}$ (prepared with a saturated solution of the dissolved salt in an ethanol water mixture 1:1), 15 grams (119 mmol) of commercial phloroglucinol, and 20.47 grams $(238 \mathrm{mmol})$ of commercial prenol (molar ratio 1:2) are added; the mixture is homogenized and irradiated at minimum power $(52.35 \mathrm{~W})$ at $50^{\circ} \mathrm{C} \pm 5^{\circ} \mathrm{C}$. After the irradiation time between each round, the temperature of the sample is measured and the reaction is cooled, immersing the glass bottles in ice water (around $4{ }^{\circ} \mathrm{C}$ ). The dry mixture is again subjected to microwave irradiation with the same conditions of microwave power and time. After the first reaction only silica- $\mathrm{AgNO}_{3}$ impregnated with phloroglucinol recovered from the filtrate in the same above reaction is added, plus 5 grams $(58 \mathrm{mmol})$ of prenol each repetition; thus ensuring that all the phloroglucinol react. This process is repeated until all the starting phloroglucinol has reacted; this can be verified by TLC monitoring. After the reaction, the $\mathrm{AgNO}_{3}$ must be removed from the reaction; this is done by doing 2 washes in a 1:1 ratio $\mathrm{NaCl}$ and dichloromethane saturated solution in a separating funnel.

The mixtures obtained from the synthesis of prenyl- and geranyl-derivatives were not stirred during the reaction. The crude product was isolated by silica gel column chromatography with $15 \%$ ethyl acetate in $n$-hexane, and the compounds were characterized by NMR, IR and Mass spectra.

\subsection{Characterization Data}

Compound 4(E)-2-(3,7-dimethylocta-2,6-dienyl)-1,3,5-trihydroxy benzene: $(14.2435 \mathrm{~g}, 45.6 \%)$; ${ }^{1} \mathrm{H}-\mathrm{NMR}$ : 5.95 (s, $2 \mathrm{H}, \mathrm{H}-4$ and $\left.\mathrm{H}-6\right) ; 5.24$ (br.t., $1 \mathrm{H}$, $\mathrm{H}-2^{\prime}$ ); 5.04 (br.t., $\left.1 \mathrm{H}, \mathrm{H}-6^{\prime}\right) ; 3.34$ (d, $\left.J=6.9 \mathrm{~Hz}, 2 \mathrm{H}, \mathrm{H}-1^{\prime}\right) ; 2.08$ (m, 4H, H-4' and $\left.\mathrm{H}-5^{\prime}\right) ; 1.78$ (s, 3H, $\left.\mathrm{CH}_{3}-\mathrm{C}^{\prime}\right) ; 1.66\left(\mathrm{~s}, 3 \mathrm{H}, \mathrm{H}-8^{\prime}\right) ; 1.58\left(\mathrm{~s}, 3 \mathrm{H}, \mathrm{CH}_{3}-\right.$ C7'). ${ }^{13} \mathrm{C}-\mathrm{NMR}: 155.7$ (C-1 y C-3), 154.9 (C-5), 139.0 (C-3'), 132.1 (C-7'), 123.7 (C-6'), 121.9 (C-2'), 106.0 (C-2), 96.0 (C-4 and C-6), 39.6 (C-4'), 26.3 (C-5'), $25.6\left(\mathrm{C}-8^{\prime}\right), 21.9\left(\mathrm{C}-1^{\prime}\right), 17.7\left(\mathrm{CH}_{3}-\mathrm{C}^{\prime}\right) ; 16.1\left(\mathrm{CH}_{3}-\mathrm{C} 7^{\prime}\right)$; IR $\left(\mathrm{cm}^{-1}\right)$ : $3397,2967,2925,1706,1620,1515,1463,1377$

Compound 5 2,6-bis-((E)-(3,7-dimethylocta-2,6-dienyl)-1,3,5-trihydroxy benzene:(3.38g, 7.1\%); ${ }^{1} \mathrm{H}-\mathrm{NMR}: 5.96$ (s, $\left.1 \mathrm{H}, \mathrm{H}-4\right) ; 5.24$ (br. t.,2H, H-2'); 5.04 (br. t., $\left.2 \mathrm{H}, \mathrm{H}-6^{\prime}\right) ; 3.34$ (d, $J=6.9 \mathrm{~Hz}, 4 \mathrm{H}, \mathrm{H}-1^{\prime}$ ); 2.08 (m, 8H, H-4' and 5'); 1.78 (s, 6H, $\left.\mathrm{CH}_{3}-\mathrm{C} 3^{\prime}\right) ; 1.66$ (s, 6H, H-8'); 1.58 (s, 6H, $\left.\mathrm{CH}_{3}-\mathrm{C} 7^{\prime}\right) .{ }^{13} \mathrm{C}-\mathrm{RMN}: 155.7$ (C-1); 154.9 (C-3 and C-5); 138.9 (C-3'); 132.1 (C-7'); 123.7 (C-6'); 122.2 (C-2'); 106.0 (C-2 and C-6); 96.0 (C-4); 39.6 (C-4'); 26.3 (C-5'); 25.6 (C-8');
21.9 (C-1'); $17.7\left(\mathrm{CH}_{3}-\mathrm{C}^{\prime}\right) ; 16.1\left(\mathrm{CH}_{3}-\mathrm{C}^{\prime}\right)$. IR $\left(\mathrm{cm}^{-1}\right): 3440,2967,2923$, 2849, 1622, 1449, 1376. HRMS (MALDI-TOF, $m / z)$ : $[\mathrm{M}+\mathrm{H}]^{+}$calculated for $\mathrm{C}_{26} \mathrm{H}_{39} \mathrm{O}_{3}, 399.2899$; observed, 399.2587 (intensity $37 \%$ ).

Compound 6 (E)-2-(3-methylbuta-2-enyl)-1,3,5-trihydroxy benzene: (12.34g, 49.9\%); ${ }^{1} \mathrm{H}-\mathrm{NMR}$ : 5.94 (s, $2 \mathrm{H}, \mathrm{H}-4$ and $\mathrm{H}-6$ ); 5.24 (br.t., $1 \mathrm{H}, \mathrm{H}-2$ '); $3.33\left(\mathrm{~d}, J=7.1 \mathrm{~Hz}, 2 \mathrm{H}, \mathrm{H}-1^{\prime}\right) ; 1.81$ (s, 3H, $\left.\mathrm{CH}_{3}-\mathrm{C}^{\prime}\right) ; 1.75$ (s, 3H, H-4'). ${ }^{13} \mathrm{C}-$ NMR: 155.7 (C-1 y C-3), 155.0 (C-5), 135.4 (C-3'), 122.0 (C-2'), 105.9 (C-2), 96.0 (C-4 and C-6), $25.8\left(\mathrm{C}-4^{\prime}\right), 22.0\left(\mathrm{C}-1^{\prime}\right), 17.8\left(\mathrm{CH}_{3}-\mathrm{C} 3^{\prime}\right)$; IR $\left(\mathrm{cm}^{-1}\right)$ : 3391 $(\mathrm{OH}), 2974$ (C-H alkane), $2926(\mathrm{C}-\mathrm{H}$ alkane), $1616(\mathrm{C}=\mathrm{C}$ aromatic $), 1517$, $1465,1375,1284,1230,1144$

Compound 7 2,6-bis-((E)-(3-methylbuta-2-enyl)-1,3,5-trihydroxy benzene: $(5.3188 \mathrm{~g}, 18.1 \%)$; ${ }^{1} \mathrm{H}-\mathrm{NMR}$ : $5.95(\mathrm{~s}, 1 \mathrm{H}, \mathrm{H}-4) ; 5.51(1-\mathrm{OH}) ; 5.24$ (br. t., $\left.2 \mathrm{H}, \mathrm{H}-2^{\prime}\right) ; 5.02(3,5-\mathrm{OH}) ; 3.34\left(\mathrm{~d}, J=7.0 \mathrm{~Hz}, 4 \mathrm{H}, \mathrm{H}-1^{\prime}\right) ; 1.82\left(\mathrm{~s}, 6 \mathrm{H}, \mathrm{CH}_{-}-\right.$ $\mathrm{C}^{\prime}$ ); 1.76 (s, 6H, H-4'). ${ }^{13} \mathrm{C}-\mathrm{RMN}$ : 154.0 (C-1); 153.1 (C-3 and C-5); 135.2 (C-3'); 122.2 (C-2'); 106.0 (C-2 and C-6); 95.9 (C-4); 39.6 (C-4'); 25.8 (C-4'); $22.3\left(\mathrm{C}-1^{\prime}\right) ; 17.8\left(\mathrm{CH}_{3}-\mathrm{C}^{\prime}\right)$. IR $\left(\mathrm{cm}^{-1}\right): 3434(\mathrm{OH}), 2971,2915,2857(\mathrm{C}-\mathrm{H}$ alkanes), 1623 (C=C aromatic), 1508, 1449, 1375, 1260, 1226, 1168, 1085.

\section{RESULTS AND DISCUSSION}

The best reaction conditions depended on the nature of the allyl alcohol used. Based on this it was possible to determine that for the alkylation of phloroglucinol with geraniol, the optimum time of each round of radiation (at low power: $52.35 \mathrm{~W}$ ) was 5 minutes, with $4-5$ rounds of irradiation (See yields in Table 1). Experimentally we observed that when more than 5 minutes of irradiation time elapsed the sample overheated, lowering the expected yield of the reaction. This reaction protocol allowed us to use a total of 15 grams of phloroglucinol distributed equally among several bottles, repeating the reaction process 4-5 times (rounds), reusing the same silica- $\mathrm{AgNO}_{3}$ and phloroglucinol until the starting material could not observed by TLC (Figure 1).On the other hand, the ideal times for mixing with prenol were shorter than those with geraniol, 4-6 rounds of 2 minutes maximum each. This reaction protocol allowed us to use a total of 15 grams of phloroglucinol equally distributed among several bottles, repeating the reaction process 4-6 times (rounds), reusing the same initial silica- $\mathrm{AgNO}_{3}$ and phloroglucinol until the starting material could not be seen by TLC (Figure 1).Similar to the reaction with geraniol, in the alkylation with prenol the irradiation time is critical to the success of the reaction- in this case after 2 minutes the start of calcination of the reagents is observed.

In both cases of alkylation, with prenol or geraniol, the predominance of the mono-alkylated molecule with yield percentages of about $50 \%$ is observed, and in a smaller fraction the dialkylated molecules observed with lower values. It should be noted that the yields observed reflect better results when the alkylation involves a shorter carbon chain as in the case of prenol; this may be due to a possible steric effect.

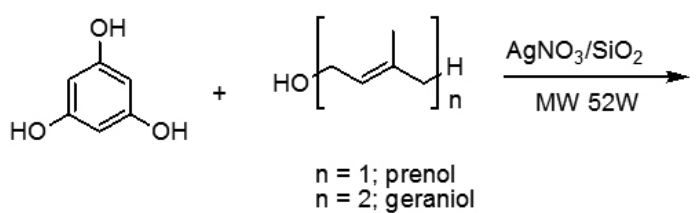

Scheme 1 Alkylation of phloroglucinol with allylic alcohol.

In search for the best conditions of alkylation, standardized tests were performed using the coupling reaction of phloroglucinol with geraniol keeping track of the mono-alkylated product, in such a way as to imitate the conditions for the case of the coupling with prenol. The strategy was to choose four catalysts, indicated in literature ${ }^{17,18}$, that were used in such reactions, which were used in conjunction with 2 solid supports $\left(\mathrm{SiO}_{2}\right.$ and $\left.\mathrm{K} 10\right)$. To carry out the reaction, the starting materials in 3 different types of solvent were added (these solvents were chosen by their degree of polarity which allowed the dissolving of phloroglucinol with geraniol, acetonitrile $>$ ethanol $>$ dichloromethane) and the absence of them (Free Solvents), evaluating the irradiation time and temperature. Time is a key point in the reaction method; it was observed that prolonged exposure to irradiation (more than 5 minutes in each round) causes an increase in the solvent temperature, directly affecting the reaction efficiency (yield). Whereas when the solvent variable was removed, more irradiation time was given to the reaction, obtaining better performance $(10 \mathrm{x})$. Temperature is an important factor to consider because if it increases rapidly it destroys the starting material (allyl alcohol); having this variable controlled, it is possible to improve the performance giving successive rounds of irradiation with cool- ing breaks, which can only be achieved successfully with the support being impregnated with the catalyst.

The reaction of alkylation of phloroglucinol resulted in 4 compounds, 2 mono-alkylated compounds $(4,6)$ and 2 di-alkylated compounds $(5,7)$, where compound $\mathbf{5}$ correspond to a new compound (Table 3 ).

Regioselectivity is fundamental for this methodology and is achieved from the key step of $\mathrm{Ag}^{+}$coordination to both the phenol and allylic alcohol. After coordination, the allylic residue could be placed in the nearest position to the phenol substrate. Immediately afterwards the active ortho position of the phenol ring could attack and then react with the allylic carbon with positive charge density. Similar alkylation mechanism was proposed for $C$-acylation of phenols and naphtols derivatives catalyzed by modified $\mathrm{ZnCl}_{2}$ on $\mathrm{Al}_{2} \mathrm{O}_{3}$ as catalyst under solvent-free and microwave conditions ${ }^{19-20}$. A possible interaction of Ag (I) complex coordinate to allylic alcohol with the possible formation of highly reactive allylic carbocationic intermediates was reported ${ }^{21}$. Also, the allylation position was primarily the less sterically hindered of all the molecules produced. 


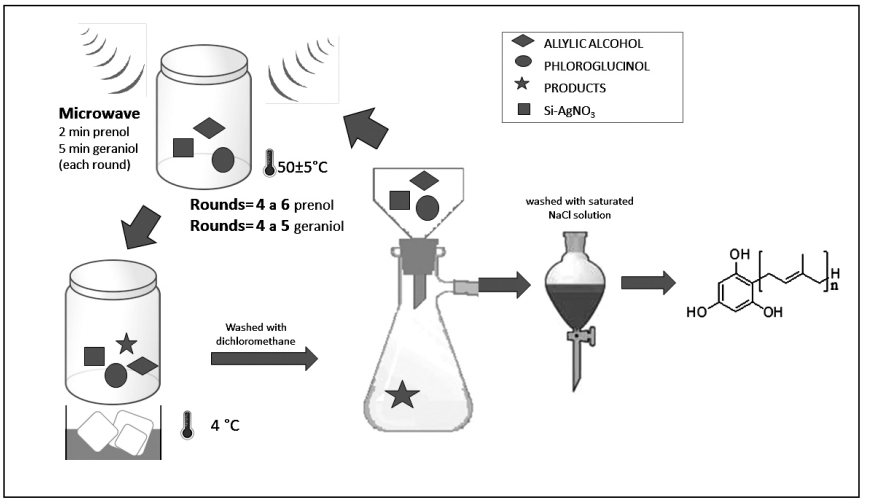

Figure 1.Diagram of synthesis protocol of alkylated phloroglucinols by microwave irradiation.

Table 1. Different Lewis acid and supporting material used to catalyze the Friedel-Crafts reaction between phloroglucinol and geraniol.

\begin{tabular}{|c|c|c|c|c|c|c|}
\hline S.no. & Catalyst & Support & Solvent & Time (min.) & Temp. $\left({ }^{\circ} \mathrm{C}\right)$ & Yield $(\%)$ \\
\hline \multirow{8}{*}{1} & \multirow{8}{*}{$\mathrm{AlCl}_{3}$} & \multirow[t]{4}{*}{$\mathrm{SiO}_{2}$} & Acetonitrile & 4 & 50 & 2 \\
\hline & & & ethanol & 2 & 50 & 3 \\
\hline & & & dichloro & 2 & 50 & 1 \\
\hline & & & $\mathrm{F} / \mathrm{S}$ & 10 & 45 & $\mathrm{~s} / \mathrm{r}$ \\
\hline & & \multirow[t]{4}{*}{ K10 } & Acetonitrile & 3 & 45 & 4 \\
\hline & & & ethanol & 2 & 45 & 2 \\
\hline & & & dichloro & 2 & 45 & 2 \\
\hline & & & $\mathrm{F} / \mathrm{S}$ & 10 & 45 & $\mathrm{~s} / \mathrm{r}$ \\
\hline \multirow{8}{*}{2} & \multirow{8}{*}{$\mathrm{ZnCl}_{2}$} & \multirow[t]{4}{*}{$\mathrm{SiO}_{2}$} & Acetonitrile & 4 & 55 & 3 \\
\hline & & & ethanol & 5 & 55 & 4 \\
\hline & & & dichloro & 6 & 55 & 1 \\
\hline & & & $\mathrm{F} / \mathrm{S}$ & 15 & 50 & $\mathrm{~s} / \mathrm{r}$ \\
\hline & & \multirow[t]{4}{*}{ K10 } & Acetonitrile & 5 & 50 & 4 \\
\hline & & & ethanol & 5 & 55 & 1 \\
\hline & & & dichloro & 5 & 45 & 1 \\
\hline & & & $\mathrm{F} / \mathrm{S}$ & 20 & 50 & $\mathrm{~s} / \mathrm{r}$ \\
\hline \multirow{8}{*}{3} & \multirow{8}{*}{$\mathrm{PdCl}_{2}$} & \multirow[t]{4}{*}{$\mathrm{SiO}_{2}$} & Acetonitrile & 2 & 50 & 2 \\
\hline & & & ethanol & 2 & 45 & 3 \\
\hline & & & dichloro & 2 & 50 & 2 \\
\hline & & & $\mathrm{F} / \mathrm{S}$ & 15 & 50 & 1 \\
\hline & & \multirow[t]{4}{*}{ K10 } & Acetonitrile & 3 & 40 & 1 \\
\hline & & & ethanol & 2 & 45 & 2 \\
\hline & & & dichloro & 2 & 50 & 1 \\
\hline & & & $\mathrm{F} / \mathrm{S}$ & 15 & 50 & $\mathrm{~s} / \mathrm{r}$ \\
\hline \multirow{8}{*}{4} & \multirow{8}{*}{$\mathrm{AgNO}_{3}$} & \multirow[t]{4}{*}{$\mathrm{SiO}_{2}$} & Acetonitrile & 2 & 45 & 5 \\
\hline & & & ethanol & 3 & 45 & 4 \\
\hline & & & dichloro & 2 & 45 & 4 \\
\hline & & & $\mathrm{F} / \mathrm{S}$ & 5 & 50 & 46 \\
\hline & & \multirow[t]{4}{*}{ K10 } & Acetonitrile & 2 & 50 & 5 \\
\hline & & & ethanol & 2 & 50 & 4 \\
\hline & & & dichloro & 2 & 50 & 3 \\
\hline & & & $\mathrm{F} / \mathrm{S}$ & 15 & 50 & 20 \\
\hline
\end{tabular}


Once certain critical variables are determined, work is done with the different physicochemical properties of the support together with the catalyst. Table 2 shows the variables that were evaluated to improve the synthesis; at this stage various solid supports were used with and without catalyst (silver nitrate), obtaining the yields described in the table.

Table 2. Different supports for the geranylation of phloroglucinol using silver nitrate as catalyst.

\begin{tabular}{|c|c|c|}
\hline Entry & Reagent & Yields \% \\
\hline 1 & Montmorillonite $\mathrm{K} 10$ & 5 \\
\hline 2 & $\mathrm{AgNO}_{3}-\mathrm{K} 10$ & 12 \\
\hline 3 & $\mathrm{SiO}_{2}$ acid & 4 \\
\hline 4 & $\mathrm{SiO}_{2}$ basic & 4 \\
\hline 5 & $\mathrm{SiO}_{2}$ neutra & 5 \\
\hline 6 & $\mathrm{AgNO}_{3}-\mathrm{SiO}_{2}$ acid & 35 \\
\hline 7 & $\mathrm{AgNO}_{3}-\mathrm{SiO}_{2}$ basic & 40 \\
\hline 8 & $\mathrm{AgNO}_{3}-\mathrm{SiO}_{2}$ neutral & 49 \\
\hline
\end{tabular}

Table 3. Reaction allyl alcohol of aromatics with silver nitrate adsorbed on silica gel.

(1) Marting Materials

\section{CONCLUSIONS}

The importance of these compounds (alkylated derivatives of floroglucinol) lies in their biological potential, which is widely described. To propose a synthesis method of short time and low cost (compared to classical synthesis methods) that promotes protection of the environment is an interesting alternative, when increasing production is necessary. This methodology differs in many respects from conventional chemical synthesis based on Friedel-Crafts reaction. This protocol provides the synthesis procedure in a dry atmosphere without organic solvents that dissolve reaction reagents. The support used for this "dry" reaction is silica gel that facilitates the provision of phloroglucinol during the reaction. Using $\mathrm{AgNO}_{3}$, a less toxic catalyst instead of the commonly used $\mathrm{BF}_{3}, \mathrm{AlCl}_{3}, \mathrm{SnCl}_{4}, \mathrm{AuCl}_{3}$, etc. was shown to be beneficial to the reaction due to the probable stabilization of the double bond allyl. The use of microwaves, despite being in this case a domestic and non-professional apparatus, shows that the reaction by heating occurs in short irradiation times $(2$ to 5 minutes at low power), since it is limited by the physicochemical properties of allyl alcohol which is sensitive to temperature. The conditions of this methodology allow for the production of higher amounts (grams) in a short time without using solvents- beating the reaction yields reported by classical methods of synthesis, and reaching yields close to $50 \%$. The conditions of this methodology allow to produce higher amounts in the order of grams in a short time without spending solvents, beating reaction yields reported by classical methods of synthesis, reaching yields close to $50 \%$. 


\section{ACKNOWLEDGEMENTS}

Financial support from the FONDECYT (Research Grant Nº11121440) is gratefully acknowledged. We also thank Dr. Manuel González (Universidad Nacional de Rosario, Argentina) for his help in NMR analysis and advice.

\section{REFERENCES}

1. Quang, D. N.; Hashimoto, T.; Arakawa, Y.;Kohchi, C.,Nishizawa, T.; Soma, G. I., Asakawa, Y. Bioorg. Med. Chem.14, 164 (2006)

2. Bauer, J.; Koeberle, A.; Dehm, F.; Pollastro, F.; Appendino, G.; Northoff, H.; Rossi, A., Sautebin, L.,Werz, O.Biochem. Pharmacol.81, 259 (2011)

3. Danelutte, A. P.; Lago, J. H. G.; Young, M. C. M.; Kato, M. J.Phytochemistry.64, 555 (2003)

4. Manfredi, K. P.; Vallurupalli, V.; Demidova, M., Kindscher, K.; Pannell, L. K. Phytochemistry. 58, 153 (2001)

5. Jung, H. A.;Jin, S. E.; Park, J-S.; Choi, J. S.Phytother. Res.25, 709 (2011)

6. Han, Q-B.; Qiao, C-F.; Song, J-Z.; Yang, N-Y.; Cao, X-W.; Peng, Y.; Yang, D-J.; Chen, S-L.; Xu, H-X.Chem. Biodiv.4, 940 (2007)

7. Liu, Q.; Shu, X.; Wang, L.; Sun, A.; Liu, J.; Cao, X.Cell Mol. Immunol.5, 271 (2008)

8. Osorio, M.; Aravena, J.; Vergara, A., Taborga, L.; Baeza, E.; Catalán, K.; González, C.; Carvajal, M.; Carrasco, H.; Espinoza, L.Molecules.17, 556 (2012)
9. Rueping, M.;Nachtsheim, B. J.Beilstein J. Org. Chem.6, 1 (2010)

10. Talhi, Q.; Silva, A. M.S.Curr. Org. Chem.17, 1067 (2013)

11. Masao,Tsukayama.; Makoto, Kikuchi.;Yasuhiko, Kawamura.Chem. Lett.7,1203 (1994)

12. Paz, L.; Rodrigues, J. A. R.J. Braz. Chem. Soc.14, 975 (2003)

13. Taborga, L.; Vergara, A.; Fernández, M. J.; Osorio, M.; Carvajal, M.; Madrid, A.; Marilaf, F.; Carrasco, H.; Espinoza, L.J. Chil. Chem. Soc. 58, 1790 (2013)

14. Tingting, He.;Zhenggen, Zha.; Chongfeng, Pan.; Zhiyong, Wang. Synth. Commun.37, 849 (2007)

15. Hegedus, L. S. Transition Metals in the Synthesis of Complex Organic Molecules; $2^{\text {nd }}$ Edition, University Science Books: Sausalito, CA, 1999.

16. Naodovic, M.; Yamamoto, H.Chem. Rev.108, 3132 (2008)

17. Benzouhanava, C.; Al Zihari, M.A. Appl. Catal. 8, 45 (1992)

18. Sugunan, S.; Renuka, N.K. Indian Journal of Chemistry. 40A, 191-194 (2001)

19. Naeimi, H.; Amini, A.; Moradian, M.Org. Chem. Front., 1, 415 (2014). DOI: $10.1039 / \mathrm{c} 4 q 000031 \mathrm{e}$

20. Bálint, E; Kovács O.; Drahos L.; Keglevich G. Letter in Organic Chemistry., 10,330-336 (2013)

21. Bandini, M; Eichholzer, A.; Kotrusz, P.; Tragni, M.; Troisi, S.; UmaniRonchi, A. Adv. Synth. Catal., 351, 319 - 324 (2009). DOI: 10.1002/ adsc. 200800628 